\title{
Engineering Mathematical Analysis Method for Productivity Rate in Linear Arrangement Serial Structure Automated Flow Assembly Line
}

\author{
Tan Chan Sin, ${ }^{1}$ Ryspek Usubamatov, ${ }^{1}$ M. A. Fairuz, ${ }^{2}$ \\ Mohd Fidzwan B. Md. Amin Hamzas, ${ }^{1}$ and Low Kin Wai ${ }^{1}$ \\ ${ }^{1}$ School of Manufacturing Engineering, Universiti Malaysia Perlis, 02600 Arau, Perlis, Malaysia \\ ${ }^{2}$ Faculty of Engineering Technology, Universiti Malaysia Perlis, 02600 Arau, Perlis, Malaysia \\ Correspondence should be addressed to Tan Chan Sin; tcs5077@gmail.com
}

Received 29 June 2014; Revised 29 October 2014; Accepted 13 November 2014

Academic Editor: Qing-Wen Wang

Copyright (C) 2015 Tan Chan Sin et al. This is an open access article distributed under the Creative Commons Attribution License, which permits unrestricted use, distribution, and reproduction in any medium, provided the original work is properly cited.

Productivity rate $(Q)$ or production rate is one of the important indicator criteria for industrial engineer to improve the system and finish good output in production or assembly line. Mathematical and statistical analysis method is required to be applied for productivity rate in industry visual overviews of the failure factors and further improvement within the production line especially for automated flow line since it is complicated. Mathematical model of productivity rate in linear arrangement serial structure automated flow line with different failure rate and bottleneck machining time parameters becomes the basic model for this productivity analysis. This paper presents the engineering mathematical analysis method which is applied in an automotive company which possesses automated flow assembly line in final assembly line to produce motorcycle in Malaysia. DCAS engineering and mathematical analysis method that consists of four stages known as data collection, calculation and comparison, analysis, and sustainable improvement is used to analyze productivity in automated flow assembly line based on particular mathematical model. Variety of failure rate that causes loss of productivity and bottleneck machining time is shown specifically in mathematic figure and presents the sustainable solution for productivity improvement for this final assembly automated flow line.

\section{Introduction}

Manufacturing or production process is a crucial department in primary and secondary industry which usually perform automated flow line for mass and batch while manual operated line for small scale production. Automated flow line or some publication considered to be automated transfer line is categorized into two groups with regard to the arrangement which are linear type and rotor type automated flow line. Linear type is arranged in straight flow conveyor or other transport system while rotor type is set up by circular or round transport rotors $[1,2]$. For each group type of arrangement automated flow line is divided into three subgroups which are serial, parallel, and serial parallel that perform the production flow in different action. This research finding only focuses on linear type arrangement automated flow line with serial action since this type of flow line is generally applied for assembly line in automotive industry as shown in Figure 1 .

Productivity of the automated flow line is an important indicator to measure the profit and performance for production line. To measure the productivity rate for linear arrangement with serial action automated flow line, productivity theory is required for analysis use. In theory of productivity, there is a basic mathematical model to express productivity to output finished goods per input variables which is shown in (1) [4]. Output finished goods stand for the output product or service that is produced through a certain process, while input variables mean any of the inputs including human, cost, time, and raw material that help to produce the output finished goods during production time:

$$
\text { Productivity }=\frac{\text { Output Finished Goods }}{\text { Input Variables }} \text {. }
$$




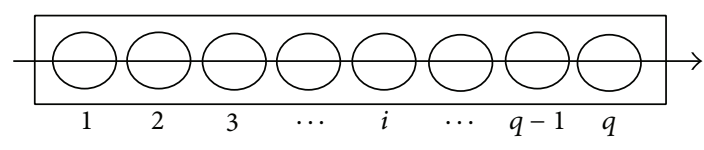

(a)

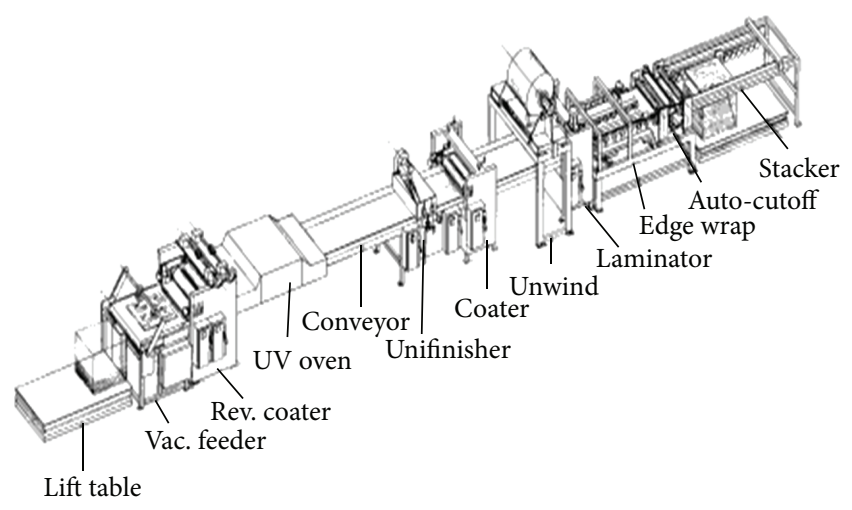

(b)

FIGURE 1: (a) Schematic diagram. (b) Example of real plant layout for linear arrangement with serial action automated flow line with $q$ stations [3].

Based on the model above presented in (1), it can be generally used to describe the productivity in a company. From this basic model, the variables of input and output can be specified and adjusted with regard to different variable, different perspective, different framework, and different application [5]. For automated flow line, engineer is required to emphasise more on the time used and output of products since both of these variables are affected by technical and technological factors of production line. Due to this condition, productivity rate $(Q)$ or production rate is developed as shown in (2) which is specifically developed from base model of productivity to fulfill the need of engineer in a production line to calculate and analyze [3]

$$
\text { Productivity Rate }(Q)=\frac{\text { number of parts produced }(z)}{\text { time used }(\theta)} \text {. }
$$

Equation (2) presents productivity rate $(Q)$ into number of parts produced $(z)$ per time used to produce $z$ parts $(\theta)$ which produce the yield of $Q$ with unit of parts/minute or parts/hour eventually. Output of this productivity rate model is very helpful for production engineers to go through and analyze the productivity level of the automated flow line for further improvement. Since $Q$ is a useful indicator for automated flow line, this model is elaborated based on reliability theory and developed a mathematical model of productivity rate with average level failure rate of workstation $\left(Q_{\text {a.f.r. }}\right)$ that is shown in (3) [6]. There are a few parameters included which are as follows: $t_{m o}$ is total machining time, $t_{a}$ is auxiliary time, $q$ is total number of serial stations, $m_{r}$ is mean time to repair, $\lambda_{s . i}$ is average failure rate per station in automated flow line, $\lambda_{c}$ is failure rate of control system, and $\lambda_{\mathrm{tr}}$ is failure rate of transport system in the line:

$$
\begin{aligned}
& \text { Productivity Rate, } Q_{\text {a.f.r }} \\
& =\frac{1}{\left(t_{m o} / q+t_{a}\right)\left[1+m_{r}\left(q \lambda_{\mathrm{s} . i}+\lambda_{c}+\lambda_{\text {tr }}\right)\right]} .
\end{aligned}
$$

Because of the mathematical model of productivity rate with average level failure rate of workstation, $\left(Q_{\text {a.f.r. }}\right)$ does not consider a few of the important parameters that will affect productivity rate for automated flow line. Mathematical model of productivity rate with different failure rate of station $\left(Q_{\text {d.f.r }}\right)$ has been developed due to consideration of several important parameters which are different workstation failure rate with theory of probability, bottleneck machining time correction factor with mathematic theory, and defect parts failure rate with reliability theory [3]. The mathematical model of productivity rate with different station failure rate is shown in (4) with several of parameters that are the same with (3) which are stated above and a few new parameters added in (4) which are as follows: $f_{m}$ is the correction factor due to bottleneck machining time in the line, $\sum_{i=1}^{q} \lambda_{s, i}$ is representing the summation of total different failure rate of each station, and $\lambda_{d}$ is failure rate of defect raw material and finished goods. This mathematical model consists of two parts which are technical part multiplied with reliability part as shown in

$$
\begin{aligned}
& \text { Productivity Rate, } Q_{\text {d.f.r }} \\
& =\frac{1}{\left(\left(t_{m o} / q\right) f_{m}+t_{a}\right)} \times \frac{1}{\left[1+m_{r}\left(\sum_{i=1}^{q} \lambda_{s . i}+\lambda_{c}+\lambda_{\mathrm{tr}}+\lambda_{d}\right)\right]} .
\end{aligned}
$$

Equation (4) presents the mathematical model of productivity with different stations failure rates which theoretically shows that it is providing higher accuracy result for forecasting and analysing the actual productivity rate when compared to (3) since (4) covers up mostly all parameters which will affect productivity rate. Since a new robust mathematical model of productivity rate for linear arrangement serial action automated flow line is developed, it is complex and inconvenient to apply in real industry by engineers.

In engineering field, mathematic theory and application become a basic tool for design and analysis work such as network, biomedical, and manufacturing engineering as well as with mathematical model or mathematical analysis [7, 8]. Mathematical method generally combines with statistical method in analysis stage which is graphical presented with 


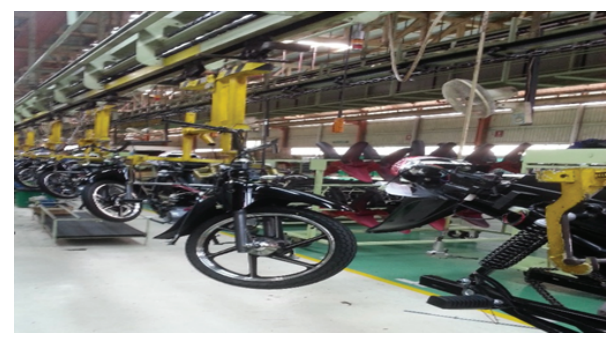

FIgURE 2: Final assembly line in ABC Company which produces $\mathrm{X}$ type motorcycle.

support of mathematical calculation. This method is considered mathematical and statistical analysis method since it involves mathematical model application and statistical analysis method $[9,10]$. Due to the high complexity of applying the mathematical model in (4) in industry, the demand for less complicated, convenient, and effective engineering mathematical and statistical analysis method is strongly needed for the automated flow line productivity rate [11].

This research paper presents the real industry validation for this mathematical model in (4) by using mathematical analysis method with help of statistical method in one company which obtained an assembly automated flow line. This paper will also present a set of engineering mathematical methods to apply the mathematical model into real industry condition systematically and conveniently which included the analysis and improvement of productivity rate in particular automated flow line. Consequently, this research presents the mathematical model of productivity rate which is assisted by engineering mathematical method to solve the productivity rate analysis problem in industry.

\section{Methodology}

For this research, a company is required to be attached to the mathematical analysis by using mathematical model and engineering mathematical method application for validation purpose. ABC Company is an automotive company in Malaysia which produces the motorcycle with automated flow line with serial action in linear arrangement in final assembly stage. This company is selected to apply the mathematical analysis method of productivity with mathematical model because it is suitable and the company is willing to collaborate with us for this research. The final assembly line of ABC Company is shown in Figure 2 which is using the automated flow line in linear arrangement serial action. There are several types of products that are assembled by using this line. For this particular validation, $\mathrm{X}$ type of motorcycle is selected for detail analysis and accurate data collection.

After selection of company and type for mathematical analysis method validation purpose, next step of research is to select and design the most appropriate methods to obtain better and high trustworthiness results from ABC Company. Engineering method is considered a set of methods guideline to solve engineering problem with support of engineering

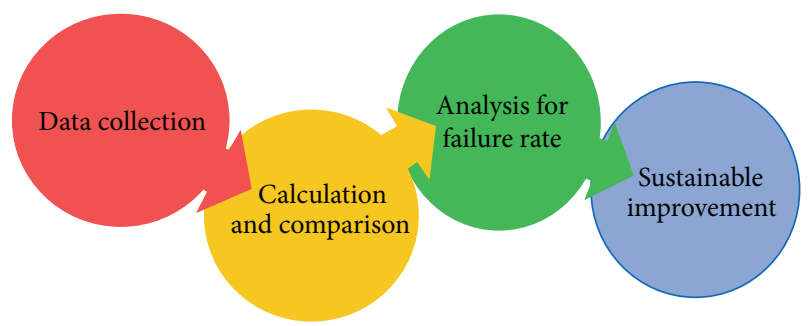

FIGURE 3: Concept of DCAS engineering mathematical analysis method to apply the mathematical model analysis in real industry.

and mathematic theory generally [12-14]. A set of engineering mathematical analysis methods are designed specifically to solve the problem of real application of complicated mathematical model of productivity which is stated in (1), (2), and (3) in industry (ABC Company). The term of engineering is applied in this method because this problem is related to manufacturing engineering and industrial engineering problem. This method as shown in Figure 3 consists of data collection, calculation and comparison, analysis for failure rate, and sustainable improvement.

Engineering mathematical analysis method which is shown in Figure 3 consists of four stages that are data collection, calculation and comparison, analysis for failure rate, and sustainable improvement which have been summarized as DCAS. The main purpose of this methods set is to overcome the inconvenient problem of real application of mathematical model of productivity in industry so that the problem can be solved by applying and following DCAS method which consists of all important way, method, analysis, and improvement to apply mathematical model. Each of the stages of methods is discussed clearly below which start from data collection (D) until the last stage, sustainable improvement (S).

(D) Data Collection. The first stage of the engineering mathematical analysis method is data collection to obtain high enough trustworthiness data for productivity and failure rate analysis. There are three categories of data required to be collected for this method usage which are actual production data, technical data, and reliability data. Detail of all data is shown clearly in Table 1.

The first category is the actual productivity data content of number of parts produced and time used using retrospective study. Retrospective study is a data collection method that refers to previous or historical data. Number of parts produced and time used are required to measure and calculate actual productivity (2) in automated flow line which presents the final and real productivity in automated flow line as guideline for mathematical model comparison use.

Technical data is a set of data regarding the technical work in automated flow line such as machining time and auxiliary time. Number of station and correction factor of bottleneck machining time are also included in technical data set because both parameters technically affect the productivity rate and these parameters can be improved via technical work. Observational study method such as time study or 
TABLE 1: Overall detail data list required for engineering mathematical analysis method.

\begin{tabular}{|c|c|c|c|c|}
\hline Data category & Collection method & Data parameter & Symbol & Unit \\
\hline \multirow{2}{*}{ Actual productivity } & \multirow{2}{*}{ Retrospective study } & Number of parts produced & $z$ & Parts \\
\hline & & Time used & $\theta$ & $\min$ or $\mathrm{sec}$ \\
\hline \multirow{4}{*}{ Technical data } & \multirow{4}{*}{ Observational study } & Total machining time & $t_{m o}$ & $\min$ or sec \\
\hline & & Auxiliary time & $t_{a}$ & $\min$ or sec \\
\hline & & Number of stations & $q$ & - \\
\hline & & Correction factor of bottleneck machining time & $f_{m}$ & - \\
\hline \multirow{5}{*}{ Reliability data } & \multirow{5}{*}{ Retrospective study } & Stations failure rate & $\lambda_{s . i}$ & $1 / \mathrm{min}$ or $1 / \mathrm{sec}$ \\
\hline & & Control system failure rate & $\lambda_{c}$ & $1 / \mathrm{min}$ or $1 / \mathrm{sec}$ \\
\hline & & Transport system failure rate & $\lambda_{\mathrm{tr}}$ & $1 / \mathrm{min}$ or $1 / \mathrm{sec}$ \\
\hline & & Defect parts failure rate & $\lambda_{d}$ & $1 / \mathrm{min}$ or $1 / \mathrm{sec}$ \\
\hline & & Mean time to repair & $m_{r}$ & $\min$ or sec \\
\hline
\end{tabular}

chronometric analysis [15], interview, and focus group is applied to obtain high confidence level data set.

Retrospective study is applied to collect reliability data such as failure rate of stations, control system, transport system, and defected parts which is related to the reliability parameters specified in failure rate of automated flow line. Mean time to repair is also considered which is calculated by total failure time divided by total frequency of failure rate. For retrospective study data, at least $90 \%$ of data trustworthiness is required for engineering data [16]. The deviation of $10 \%$ is calculated due to the total of $\pm 5 \%$ from the mean value and it is calculated using

$$
\delta_{i}=\frac{\sum_{i=1}^{n} z_{i}-z_{\mathrm{av}}}{z_{\mathrm{av}}} .
$$

Deviation $\delta_{i}$ is presented in (5) which is the yield of number of motorcycle produced in $i$ shift $\left(N_{i}\right)$ minus average or mean of motorcycle produce in $i$ shift $\left(z_{\mathrm{av}}\right)$ and divided by mean $\left(z_{\mathrm{av}}\right)$. For example, average or mean of motorcycle produce in $i$ shift $\left(z_{\text {av }}\right)$ is 40 motorcycles. In order to reach $90 \%$ of statistical trustworthiness, the deviation $\left(\delta_{i}\right)$ is required to be in the range of $\pm 5 \%$. For this $\pm 5 \%, z_{i}$ becomes \pm 2 motorcycles as upper and lower limit. Consequently, to reach $90 \%$ of statistical trustworthiness, the $z_{i}$ value is required to be converted to average mean cumulative number since the production of motorcycle is usually highly fluctuated reaching the range of $40 \pm 2$ motorcycles. Since the data collection includes failure rate parameter, it is found that 160 times of failure are required to obtain $90 \%$ of probability trustworthiness. So to obtain $90 \%$ of statistical and probability trustworthiness, the retrospective data should consist of 160 times of failures or breakdowns of automated flow line and $\pm 5 \%$ deviation of motorcycle quantity produced. $95 \%$ of statistical and probability trustworthiness which consists of $\pm 2.5 \%$ deviation will also be determined in this research.

(C) Calculation and Comparison. The second stage of engineering mathematical analysis method is to calculate the data collected using mathematical model above and compare the yield of the calculation. Actual productivity data set is used to calculate the real or actual productivity rate of $\mathrm{X}$ type of motorcycle in final assembly automated flow line by using (2).
Both sets of technical and reliability data are applied in (3) and (4) which is mathematical model of productivity with average level and different level of failure rate. The yields of (3) and (4) are compared to the actual productivity rate in final $\mathrm{X}$ type motorcycle assembly automated flow line and the comparison is done using percentage error shown in (6). The purpose of comparing with (6) is to show which of the mathematical models of productivity can obtain more accurate result (less than $10 \%$ error) when compared to actual productivity rate:

$$
\begin{gathered}
\text { Percentage error }=\frac{\left|Q_{\mathrm{d} . f . r}-Q_{\mathrm{ac}}\right|}{Q_{\mathrm{ac}}} \times 100 \% \text { Or } \\
\text { Percentage error }=\frac{\left|Q_{\mathrm{a} . f . r}-Q_{\mathrm{ac}}\right|}{Q_{\mathrm{ac}}} \times 100 \% .
\end{gathered}
$$

(A) Analysis for Failure Rate. In analysis of failure rate stage, the tool to apply for failure rate parameter analysis is productivity losses diagram analysis tools [16]. This analysis specifically presents the losses of productivity due to different failure rate in term of graphical based on mathematical calculated result used in (4). Through this analysis, impact of parameters causing losses of productivity in final assembly automated flow line for each of the failure rate parameter is detected with regard to high impact or low impact which is presented by mathematical numbering. Pareto diagram analysis is applied to arrange and analyze the parameter that causes losses of productivity in automated flow line from the highest impact to the lowest impact parameter.

(S) Sustainable Improvement. The final stage of engineering mathematical analysis method is sustainable improvement. This stage presents the meaning of the improvement step or solution that can be applied for long term application and long term improvement [17]. Since there are a lot of parameters causing the losses of productivity rate in final assembly automated line, PACE prioritization matrix is introduced to select which parameters are preferred to be improved and which (parameters) are suggested to be maintained [18]. There are four levels in the PACE prioritization matrix which are priority, action, consider, and eliminate. Priority group 


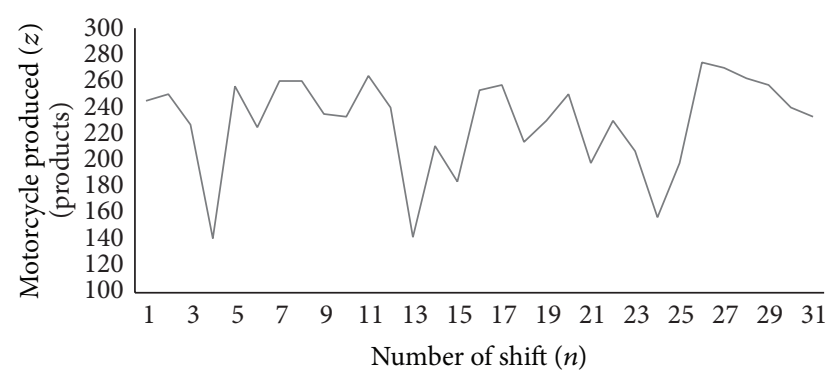

FIGURE 4: Motorcycle produced $(z)$ versus number of shift $(n)$ final assembly automated line.

parameters are preferred to proceed with improvement since it is highly affect to the productivity losses and easier to overcome when compare to others parameter. After priority group, the next preferable group for further improvement to increase the productivity of automated line is action group, followed by consider group, and last but not least is eliminate group. The grouping discussion is done by closed group and the solution is executed by the engineers.

\section{Results and Discussions}

ABC Company is selected to apply and validate the mathematical model of productivity by using engineering mathematical analysis method. Productivity rate and failure rate parameter that is causing loss of productivity in final assembly automated flow line in ABC Company are calculated and analyzed based on DCAS method. The result for each stage of engineering mathematical method is presented separately as below.

3.1. Data Collection. There are a total of three sets of data that is required to be collected in this stage for calculation and analysis use. The first set of data is actual data which includes number of shift, production time, and motorcycle produced. The actual data set for two months which are February and March 2014 in total consists of 31 shifts. Within 31 shifts of production for $\mathrm{X}$ type motorcycle, the total production is 7103 products with 14760 minutes of production time. To analyze the trustworthiness of this retrospective study data, it is required to perform the data in form of line chart to show the trend of actual products produced regarding shift as shown in Figure 4.

Figure 4 presents the motorcycle produced $(z)$ in the 31 shifts for two-month duration. Regarding Figure 4, the products per shift consist of high fluctuation and are required to be converted into average mean cumulativeness of motorcycle produced, $z_{c}$. To obtained $90 \%$ of statistical and probability trustworthiness, the deviation $\left(\delta_{i}\right)$ is required in the range of $\pm 5 \%$. Since the average or mean of motorcycle produced in $i$ shift $\left(z_{\mathrm{av}}\right)$ is 229.13 , the deviation $\left(\delta_{i}\right)$ for $\pm 5 \%$ is \pm 11.46 where the upper limit is 240.59 and lower limit is 217.67 , while for $\pm 2.5 \%$ it is \pm 5.73 where upper limit is 234.86 and lower limit is 223.4. Figure 5 presents the average mean cumulativeness for motorcycle produced according to the number of shift.

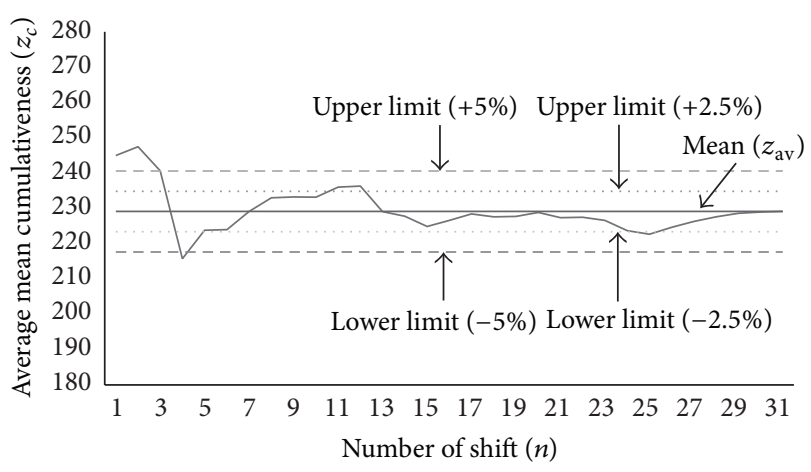

FIGURE 5: Average mean cumulativeness of motorcycle produced $\left(z_{c}\right)$ versus number of shift $(n)$.

TABLE 2: Technical data for final assembly flow line in 31 working shifts.

\begin{tabular}{lc}
\hline Title & Data \\
\hline Total machining time, $t_{m o}(\mathrm{~min})$ & 26.55 \\
Auxiliary time, $t_{a}(\mathrm{~min})$ & 0.52 \\
$\begin{array}{l}\text { Number of stations, } q \\
\text { Correction factor for machining time of the }\end{array}$ & 37 \\
bottleneck station $f_{m}$, & 1.25 \\
\hline
\end{tabular}

From Figure 5, the number of motorcycle produced in average mean cumulative form $\left(z_{c}\right)$ falls into the tolerance of $90 \%$ at shift number 7 and the fluctuation of $z_{c}$ does not fluctuate out of the range limit any more, meaning that it is stable after shift number 7. So, by collecting data from shift 7 and onwards, it consists of at least $90 \%$ of statistical trustworthiness. For higher requirement of trustworthiness which is $95 \%$, the deviation is $\pm 2.5 \%$ where the trend dropped within shifts 13-14. Within 31 shifts of motorcycle produced, there are a total 160 times of failure or breakdown occurring in the final assembly. Hence, to obtain the data set with at least $95 \%$ of statistical and $90 \%$ of probability trustworthiness, the retrospective data collection is done until shift 31 in final assembly automated flow line. Another two sets of data which are technical and reliability within 31 shifts are presented in Tables 2 and 3.

3.2. Calculation and Comparison. After data collection stage, the data collected is required to proceed to the calculation stage by using (2), (3), and (4). Equation (2) is applied to calculate actual productivity rate for final assembly automated flow line and the calculation is shown in (7). For (3), it presents the mathematical model for productivity rate with average stations failure rate. By applying the data in Table 3 into (3), the result is shown in (8). Equation (4) presents the mathematical model for productivity rate with different stations failure and (9) is the result after substituting the data above into (4).

Actual productivity rate is

$Q_{\mathrm{ac}}=\frac{z}{\theta}=\frac{7013}{14760}=0.4751$ products $/$ minute. 
Productivity rate with average station failure rate is

$$
\begin{array}{r}
Q_{\text {a.f.r }}=\frac{1}{\left(t_{m o} / q+t_{a}\right)\left[1+m_{r}\left(q \lambda_{\text {s.avg }}+\lambda_{c}+\lambda_{\text {tr }}\right)\right]} \\
=1\left(\left(\frac{26.55}{37}+0.52\right)\right. \\
\quad \times[1+11.24 \\
\quad \times\left(37 \times 4.9 \times 10^{-4}\right. \\
\left.\left.\left.\quad+9.485 \times 10^{-4}+2.033 \times 10^{-4}\right)\right]\right)^{-1}
\end{array}
$$

$=0.6641$ products $/$ minute .

Productivity rate with different station failure rate is

$$
\begin{aligned}
Q_{\text {d.f.r }}= & \frac{1}{\left(\left(t_{m o} / q\right) f_{m}+t_{a}\right)} \\
& \times \frac{1}{\left[1+m_{r}\left(\sum_{i=1}^{37} \lambda_{\mathrm{s} . i}+\lambda_{c}+\lambda_{\mathrm{tr}}+\lambda_{d}\right)\right]} \\
= & \frac{1}{[(26.55 / 37)(1.25)+0.52]} \\
& \quad \times 1([1+11.24 \\
& \quad \times\left(7.2 \times 10^{-3}+9.485 \times 10^{-4}\right. \\
& \left.\left.\left.\quad+2.033 \times 10^{-4}+3.048 \times 10^{-2}\right)\right]\right)^{-1}
\end{aligned}
$$

$=0.4911$ products $/$ minute,

Percentage error for $Q_{\text {d.f.r }}$ with $Q_{a c}$

$$
=\frac{|0.4911-0.4751|}{0.4751} \times 100 \%=3.37 \% \text {, }
$$

Percentage error for $Q_{a . f . r}$ with $Q_{a c}$

$$
=\frac{|0.6641-0.4751|}{0.4751} \times 100 \%=39.78 \% \text {. }
$$

From the productivity rate result in (8) and (9), (7) which is the actual productivity rate is used as guideline to check which mathematical model can provide more accurate result to actual result and the percentage error is calculated in (10) and (11). Regarding result of (10) and (11), it presents

\begin{tabular}{|c|c|c|}
\hline Title & $q$ & $\lambda_{\mathrm{s} . i}(1 / \mathrm{min})$ \\
\hline \multirow{37}{*}{ Failure rate of the stations $q, \lambda_{\mathrm{s}}$} & 1 & $1.355 \times 10^{-4}$ \\
\hline & 2 & $8.130 \times 10^{-4}$ \\
\hline & 3 & $4.743 \times 10^{-4}$ \\
\hline & 4 & $8.130 \times 10^{-4}$ \\
\hline & 5 & 0.000 \\
\hline & 6 & $5.420 \times 10^{-4}$ \\
\hline & 7 & 0.000 \\
\hline & 8 & 0.000 \\
\hline & 9 & $6.775 \times 10^{-5}$ \\
\hline & 10 & $4.065 \times 10^{-4}$ \\
\hline & 11 & $6.775 \times 10^{-5}$ \\
\hline & 12 & 0.000 \\
\hline & 13 & 0.000 \\
\hline & 14 & 0.000 \\
\hline & 15 & 0.000 \\
\hline & 16 & 0.000 \\
\hline & 17 & $4.065 \times 10^{-4}$ \\
\hline & 18 & $6.775 \times 10^{-5}$ \\
\hline & 19 & 0.000 \\
\hline & 20 & 0.000 \\
\hline & 21 & $6.775 \times 10^{-5}$ \\
\hline & 22 & 0.000 \\
\hline & 23 & 0.000 \\
\hline & 24 & 0.000 \\
\hline & 25 & $7.453 \times 10^{-4}$ \\
\hline & 26 & $4.065 \times 10^{-4}$ \\
\hline & 27 & $5.420 \times 10^{-4}$ \\
\hline & 28 & $5.420 \times 10^{-4}$ \\
\hline & 29 & $6.775 \times 10^{-5}$ \\
\hline & 30 & 0.000 \\
\hline & 31 & $8.130 \times 10^{-4}$ \\
\hline & 32 & 0.000 \\
\hline & 33 & $1.355 \times 10^{-4}$ \\
\hline & 34 & 0.000 \\
\hline & 35 & 0.000 \\
\hline & 36 & $6.775 \times 10^{-5}$ \\
\hline & 37 & $6.775 \times 10^{-5}$ \\
\hline \multirow{2}{*}{\multicolumn{2}{|c|}{$\begin{array}{l}\text { Total stations failure rate, } \sum_{i=1}^{37} \lambda_{\text {s.i }} \\
\text { Average station failure rate, } \lambda_{\text {s.avg }}\end{array}$}} & $7.200 \times 10^{-3}$ \\
\hline & & $4.900 \times 10^{-4}$ \\
\hline \multicolumn{2}{|c|}{ Failure rate of the control system, $\lambda_{c}$} & $9.485 \times 10^{-4}$ \\
\hline \multicolumn{2}{|c|}{ Failure rate of the transport system, $\lambda_{\mathrm{tr}}$} & $2.033 \times 10^{-4}$ \\
\hline \multicolumn{2}{|c|}{ Failure rate of the defect parts, $\lambda_{d}$} & $3.048 \times 10^{-2}$ \\
\hline \multicolumn{2}{|c|}{ Mean repair time, $m_{r}(\mathrm{~min})$} & 11.24 \\
\hline
\end{tabular}
the percentage error when compared to actual productivity rate result. Productivity rate with different station failure rate $Q_{\text {d.f.r }}$ is just $3.37 \%$ of percentage error while productivity rate with average station failure rate $Q_{\text {a.f.r }}$ obtained is $39.78 \%$ of percentage error when compared to actual productivity rate $Q_{a c}$. The reason $Q_{\text {d.f.r }}$ is not exactly same to actual is due to unexpected factors that occurred in line. Hence, it is proven and validated that mathematical model of productivity rate with different station failure rate yields the most accurate result which is less than $10 \%$ error when compared to the
TABLE 3: Reliability data for final assembly flow line in 31 working shifts.

actual result. Hence mathematical model of productivity rate with different station failure rate can be further used in more applications in the same area. Figure 6 presents the differences between $Q_{\text {d.f.r }}$ and $Q_{\text {a.f.r }}$ with respect to the number of station to prove that both models produce high differences. In Figure 6, there are three stages which are A, B, and C which 


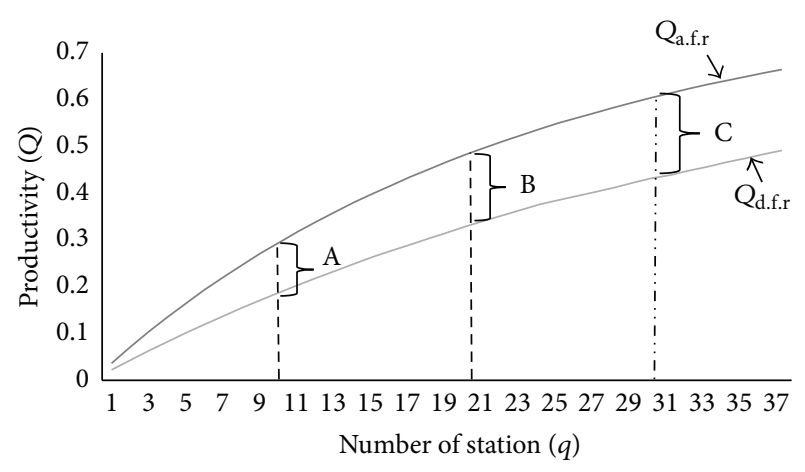

FIGURE 6: Comparison of different station failure rate productivity $\left(Q_{\text {d.f.r }}\right)$ with average station failure rate productivity $\left(Q_{\text {a.f.r }}\right)$ with respect to number of station.

present difference between $Q_{\text {d.f.r }}$ and $Q_{\text {a.f.r }}$ each 10 stations. In stage $A$, which is productivity station number 10 , the difference between both is 0.1078 . But when going to stage $B$ which is 20 stations, the difference is increased to 0.1537 and keeps increasing to 0.1725 at 30 stations in stage C. In this analysis, it is proven that the difference of $Q_{\text {d.f.r }}$ and $Q_{\text {a.f.r }}$ increases when the number of station increases. In conclusion, the higher the quantity of stations in the automated line, the higher the deviation or inaccuracy of $Q_{\text {a.f.r }}$ to actual productivity.

3.3. Analysis for Failure Rate. In this analysis for failure rate stage, each of the parameters that contributes to the losses of productivity rate in final assembly automated flow line is listed down and the value of productivity rate losses due to particular parameter is calculated. Equation below presents the calculation to determine the losses in productivity rate value and Figure 6 shows the total productivity losses diagram of final assembly automated flow line.

(a) Potential productivity:

$K=\frac{1}{\left(t_{m o} / q\right)}=\frac{1}{(26.55 / 37)}=1.3936$ products $/$ minute

(b) Cyclic productivity:

$$
\begin{aligned}
Q_{1} & =\frac{1}{\left(t_{m o} / q+t_{a}\right)}=\frac{1}{(26.55 / 37+0.52)} \\
& =0.8080 \text { products } / \text { minute }
\end{aligned}
$$

(c) Bottleneck parameter productivity:

$$
\begin{aligned}
Q_{2} & =\frac{1}{\left(\left(t_{m o} / q\right) f_{m}+t_{a}\right)}=\frac{1}{[(26.55 / 37)(1.25)+0.52]} \\
& =0.7057 \text { products/minute. }
\end{aligned}
$$

(d) Station failure rate productivity:

$$
\begin{aligned}
Q_{3}= & \frac{1}{\left(\left(t_{m o} / q\right) f_{m}+t_{a}\right)} \times \frac{1}{\left[1+m_{r}\left(\sum_{i=1}^{37} \lambda_{s . i}\right)\right]} \\
= & \frac{1}{[(26.55 / 37)(1.25)+0.52]} \\
& \times \frac{1}{1+11.24\left(7.2 \times 10^{-3}\right)} \\
= & 0.6529 \text { products } / \text { minute. }
\end{aligned}
$$

(e) Control system failure rate productivity:

$$
\begin{aligned}
Q_{4}= & \frac{1}{\left(\left(t_{m o} / q\right) f_{m}+t_{a}\right)} \times \frac{1}{\left[1+m_{r}\left(\sum_{i=1}^{37} \lambda_{s . i}+\lambda_{c}\right)\right]} \\
= & \frac{1}{[(26.55 / 37)(1.25)+0.52]} \\
& \times \frac{1}{\left[1+11.24\left(7.2 \times 10^{-3}+9.485 \times 10^{-4}\right)\right]} \\
= & 0.6462 \text { products/minute. }
\end{aligned}
$$

(f) Transport system failure rate productivity:

$Q_{5}$

$$
\begin{aligned}
& =\frac{1}{\left(\left(t_{m o} / q\right) f_{m}+t_{a}\right)} \times \frac{1}{\left[1+m_{r}\left(\sum_{i=1}^{37} \lambda_{\mathrm{s} . i}+\lambda_{c}+\lambda_{\mathrm{tr}}\right)\right]} \\
& =\frac{1}{[(26.55 / 37)(1.25)+0.52]} \\
& \times \frac{1}{\left[1+11.24\left(7.2 \times 10^{-3}+9.485 \times 10^{-4}+2.033 \times 10^{-4}\right)\right]} \\
& =0.6451 \text { products/minute. }
\end{aligned}
$$

(g) Defect failure rate productivity:

$$
\begin{aligned}
Q_{6}= & \frac{1}{\left(\left(t_{m o} / q\right) f_{m}+t_{a}\right)} \\
& \times \frac{1}{\left[1+m_{r}\left(\sum_{i=1}^{37} \lambda_{\mathrm{s} . i}+\lambda_{c}+\lambda_{\mathrm{tr}}+\lambda_{d}\right)\right]} \\
= & \frac{1}{[(26.55 / 37)(1.25)+0.52]} \\
& \times 1\left(1+11.24\left(7.2 \times 10^{-3}+9.485 \times 10^{-4}\right.\right. \\
= & 0.4911 \text { products } / \text { minute. }
\end{aligned}
$$




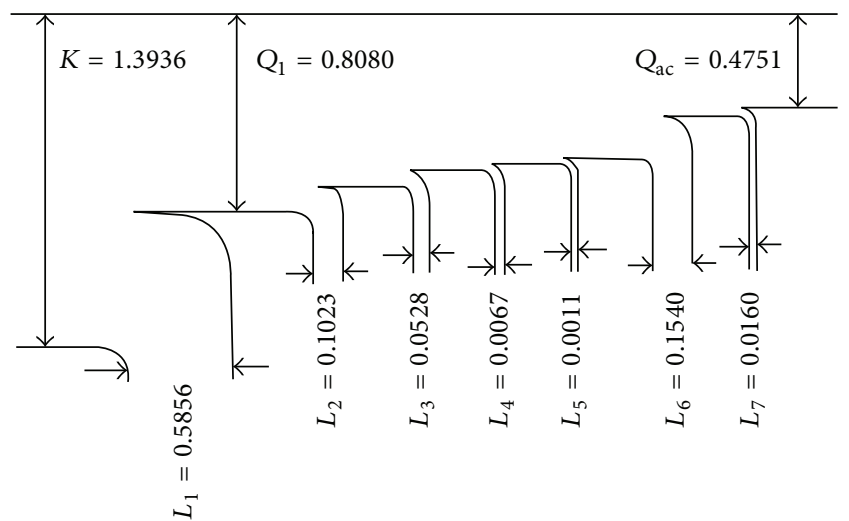

Figure 7: Total productivity losses diagram of final assembly automated flow line.

(h) Actual productivity:

$$
Q_{\mathrm{ac}}=\frac{z}{\theta}=\frac{7013}{14760}=0.4751 \text { products } / \text { minute. }
$$

(i) Losses of productivity:

$$
\begin{aligned}
L_{1} & =K-Q_{1}=1.3936-0.8080 \\
& =0.5856 \text { products } / \text { minute } \\
L_{2} & =Q_{1}-Q_{2}=0.8080-0.7057 \\
& =0.1023 \text { products } / \text { minute } \\
L_{3} & =Q_{2}-Q_{3}=0.7057-0.6529 \\
& =0.0528 \text { products } / \text { minute } \\
L_{4} & =Q_{3}-Q_{4}=0.6529-0.6462 \\
& =0.0067 \text { products } / \text { minute } \\
L_{5} & =Q_{4}-Q_{5}=0.6462-0.6451 \\
& =0.0011 \text { products } / \text { minute } \\
L_{6} & =Q_{5}-Q_{6}=0.6451-0.4911 \\
& =0.1540 \text { products } / \text { minute } \\
L_{7} & =Q_{6}-Q_{\text {ac }}=0.4911-0.4751 \\
& =0.0160 \text { products } / \text { minute. }
\end{aligned}
$$

From total productivity losses diagram in Figure 7 and (10)-(18), all of the productivity losses parameter are presented in mathematic calculation form and show in numbering result. $L_{1}$ is the losses of productivity due to auxiliary time which is 0.5856 products/minute and this parameter is the highest factor that contributes to the loss of productivity in final assembly automated flow line. $L_{2}$ is caused by bottleneck machining time in line which contributes 0.1023 products/minute, $L_{3}$ is the loss of 0.0528 products/minute due to station failure rate, $L_{4}$ is the factor of control system which is 0.0067 products/minute, $L_{5}$ is the lowest contributor factor to productivity losses due to transport problem, $L_{6}$ is 0.1540 products/minute which contribute to the second highest of losses of productivity due to the defect in raw material and finish goods, and last is $L_{7}$ which is caused by unexpected factor such as electrical breakdown that contributes 0.0160 products/minute.

After complete analyzing of the overall failure rate that causes loss of productivity, workstation within the final assembly automated flow line is required to determine the ideal number of station to obtain maximum productivity rate. For productivity with station calculation, (19) applied the mathematical model with different station failure rate but the parameter of station failure is changed to average failure rate due to lack of data of failure for the 37 stations above. For maximum productivity, the ideal number of station is determined by using (20). All of calculations are present in Figure 7. The range of $q$ station is from 10 stations until 300 stations:

$$
\begin{aligned}
Q_{q}= & \frac{1}{\left(\left(t_{\text {mo }} / q\right) f_{m}+t_{a}\right)} \\
& \times \frac{1}{\left[1+m_{r}\left(\lambda_{\text {s.avg }}+\lambda_{c}+\lambda_{\mathrm{tr}}+\lambda_{d}\right)\right]} \\
= & \frac{1}{[(26.55 / q)(1.25)+0.52]} \\
& \times 1([1+11.24 \\
q_{\mathrm{opt}}= & \sqrt{\frac{t_{m o} f_{m}\left(1 / m_{r}\right)+\lambda_{c}+\lambda_{\mathrm{tr}}+\lambda_{d}}{t_{a} \lambda_{s}}} \\
= & \left(\left(26.9 \times 10^{-4}+9.485 \times 10^{-4}\right.\right. \\
& \times[(1.25 \\
= & \left.\times\left(0.52 \times 4.9 \times 10^{-4}\right)^{-1}\right)^{1 / 2} \\
& 125.33=126 \mathrm{stations} .
\end{aligned}
$$

From Figure 8, stage A shows that the current productivity is 0.4715 products/minute at station 37 . Through calculation in (20) and particular figure, the maximum productivity that can be produced by 126 stations is 0.6228 products/minute which presents in stage $\mathrm{C}$. The productivity starts to drop after station 126 even with the increment of station. From the trend of the productivity rate, productivity is increasing drastically from stage A until stage B when the number of station is increased. Even from stage B to C, the productivity keeps on increasing, but the increment is only improved for around 5\% productivity with increment of 50 stations. From profit consideration, it is not worth that increment of around 50 stations in automated flow line for only $5 \%$ increment of productivity. Thus, the adjustment of 


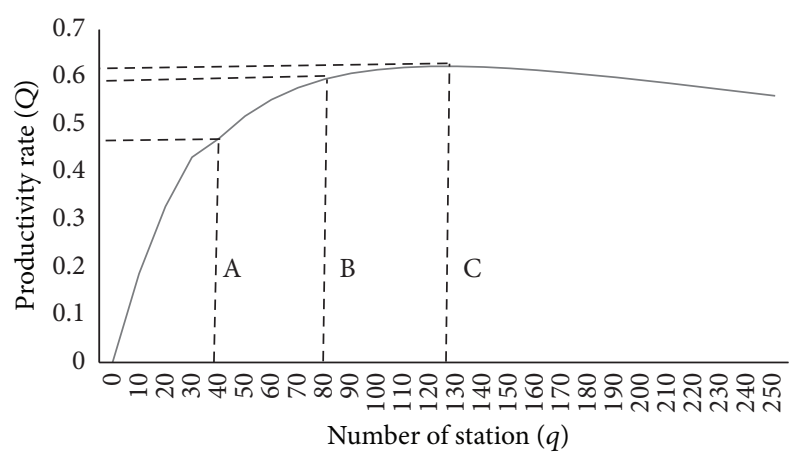

FIGURE 8: Station analysis with productivity rate versus number of station.

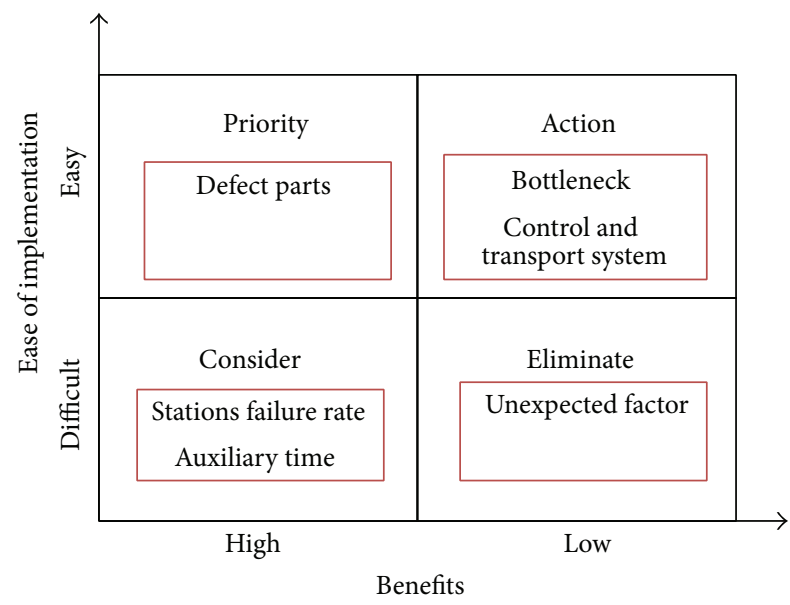

FIGURE 9: PACE prioritization matrix for final assembly automated flow line.

stations from 37 stations can increase up to 80 stations to improve the productivity profitably.

3.4. Sustainable Improvement. Final stage in DCAS engineering mathematical analysis method is sustainable improvement. Improvement process is selected by PACE prioritization matrix as shown in Figure 9 and this is the result from a closed group discussion with Production Manager and Engineer in ABC Company. Defect part parameter is preferred to be improved due to its high impact on productivity losses and because it is easier to improve than others.

\section{Conclusion}

After applying DCAS engineering mathematical analysis method in ABC Company with the help of mathematical model of productivity rate with different reliability, all of the productivity rate losses parameters are calculated, measured, and analyzed with mathematical figures. The losses and productivity of final assembly automated flow line can be analyzed visually, clearly, systematically, and effectively which is much better than just simply analyzing previous productivity. In conclusion, mathematical model of productivity rate with different station failure rate is proven and validated to be useful and more accurate than previous productivity mathematical model which obtains 3.37\% error or more than $90 \%$ accuracy. It is proved that new mathematical model produces higher accuracy result for productivity rate forecasting. DCAS engineering mathematical analysis method is also proven to be systematic and effective to be applied in linear arrangement serial action automated flow line which is the final assembly line in $\mathrm{ABC}$ Company to calculate and analyze the productivity rate in that particular line. The productivity losses parameters are determined and improved systematically with the help of mathematical model of productivity rate with different station failure rate. In the future, this mathematical model of productivity rate with different station failure rate and DCAS engineering mathematical analysis method can be applied to more field of sector such as food processing or machining automated line since this mathematical model and method can be applied generally in linear arrangement serial structure automated flow line.

\section{Conflict of Interests}

The authors declare that there is no conflict of interests regarding the publication of this paper.

\section{Acknowledgments}

Tan Chan Sin, the main author of this paper, would like to thank the Ph.D. degree supervisor, Professor Ryspek Usubamatov, for his excellent guidance. One of the authors would also like to express appreciation to the author's research partners Mr. Mohd Fidzwan B. Md. Amin Hamzas, M. A. Fairuz, and Low Kin Wai who always help in solving some technical problems.

\section{References}

[1] T. Freiheit, M. Shpitalni, and S. J. Hu, "Productivity of paced parallel-serial manufacturing lines with and without crossover," Journal of Manufacturing Science and Engineering, vol. 126, no. 2, pp. 361-367, 2004.

[2] R. Usubamatov, M. Z. Abdulmuin, A. M. Nor, and M. N. Murad, "Productivity rate of rotor-type automated lines and optimisation of their structure," Proceedings of the Institution of Mechanical Engineers, Part B: Journal of Engineering Manufacture, vol. 222, no. 11, pp. 1561-1566, 2008.

[3] R. Usubamatov, T. C. Sin, and M. F. B. Md. Amin Hamzas, "Productivity theory for industrial automated lines," in Proceedings of the Mechanical Engineering Congress \& Exhibition, pp. 1-11, ASME, 2013.

[4] S. Saari, "Theory and measurement in business," in Proceedings of the International Conference on Concurrent Engineering in Construction, no. 1/10-10/10, Espoo, Finland, 2006.

[5] S. Saari, "Production and productivity as souces of well-being," 2011.

[6] R. Usubamatov, K. A. Ismail, and J. M. Sah, "Mathematical models for productivity and availability of automated lines," International Journal of Advanced Manufacturing Technology, vol. 66, no. 1-4, pp. 59-69, 2013. 
[7] W. M. Baek, J. H. Yoon, and C. Kim, "Modeling and analysis of mobility management in mobile communication networks," The Scientific World Journal, vol. 2014, Article ID 250981, 11 pages, 2014.

[8] R. Bighamian and J.-O. Hahn, "Relationship between stroke volume and pulse pressure during blood volume perturbation: a mathematical analysis," BioMed Research International, vol. 2014, Article ID 459269, 10 pages, 2014.

[9] J. You and T. Ando, "A statistical modeling methodology for the analysis of term structure of credit risk and its dependency," Expert Systems with Applications, vol. 40, no. 12, pp. 4897-4905, 2013.

[10] J. Guo, L. Monas, and E. Gill, "Statistical analysis and modelling of small satellite reliability," Acta Astronautica, vol. 98, no. 1, pp. 97-110, 2014.

[11] C. D. Senanayake and V. Subramaniam, "Estimating customer service levels in automated multiple part-type production lines: an analytical method," Computers and Industrial Engineering, vol. 64, no. 1, pp. 109-121, 2013.

[12] G. Muller, "Systems engineering research methods," Procedia Computer Science, vol. 16, pp. 1092-1101, 2013.

[13] T. P. Thyvalikakath, M. P. Dziabiak, R. Johnson et al., "Advancing cognitive engineering methods to support user interface design for electronic health records," International Journal of Medical Informatics, vol. 83, no. 4, pp. 292-302, 2014.

[14] T. Ruiz-López, M. Noguera, M. J. Rodríguez, J. L. Garrido, and L. Chung, "REUBI: a Requirements Engineering method for ubiquitous systems," Science of Computer Programming, vol. 78, no. 10, pp. 1895-1911, 2013.

[15] G. D. Kirk, B. S. Linas, R. P. Westergaard et al., "The exposure assessment in current time study: implementation, feasibility, and acceptability of real-time data collection in a community cohort of illicit drug users," AIDS Research and Treatment, vol. 2013, Article ID 594671, 10 pages, 2013.

[16] R. Usubamatov, A. R. Riza, and M. N. Murad, "A method for assessing productivity in unbuffered assembly processes," Journal of Manufacturing Technology Management, vol. 24, no. 1, pp. 123-139, 2013.

[17] H.-Z. Quan and H. Kasami, "Experimental study on durability improvement of fly ash concrete with durability improving admixture," The Scientific World Journal, vol. 2014, 11 pages, 2014.

[18] G. S. Kaplan, "Value stream mapping-PACE matrix," in Advanced Lean Thinking: Proven Methods to Reduce Waste and Improve Quality in Health Care, H. M. Fry, Ed., p. 29, Joint Comission Resource, 2008. 


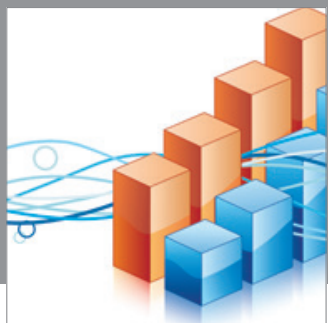

Advances in

Operations Research

mansans

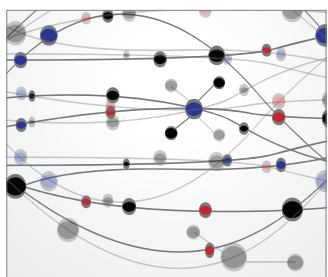

The Scientific World Journal
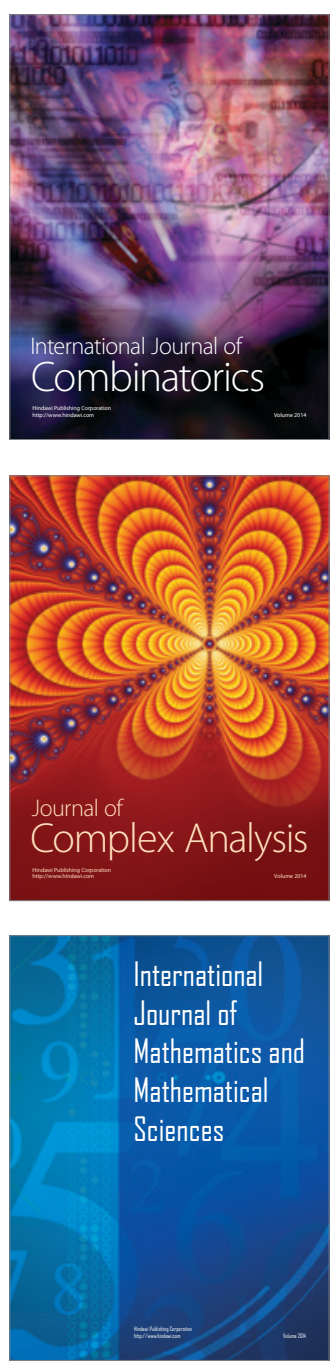
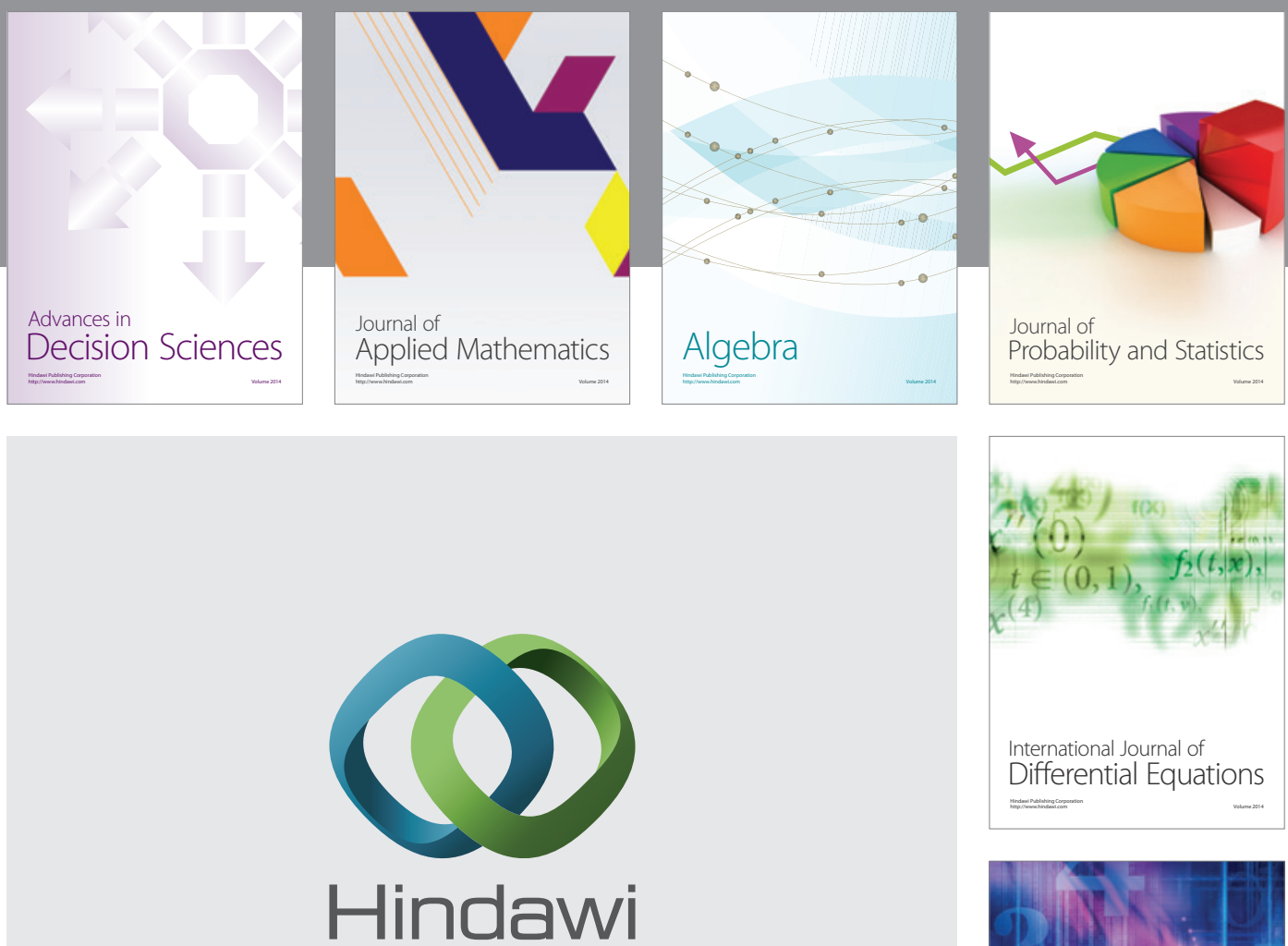

Submit your manuscripts at http://www.hindawi.com
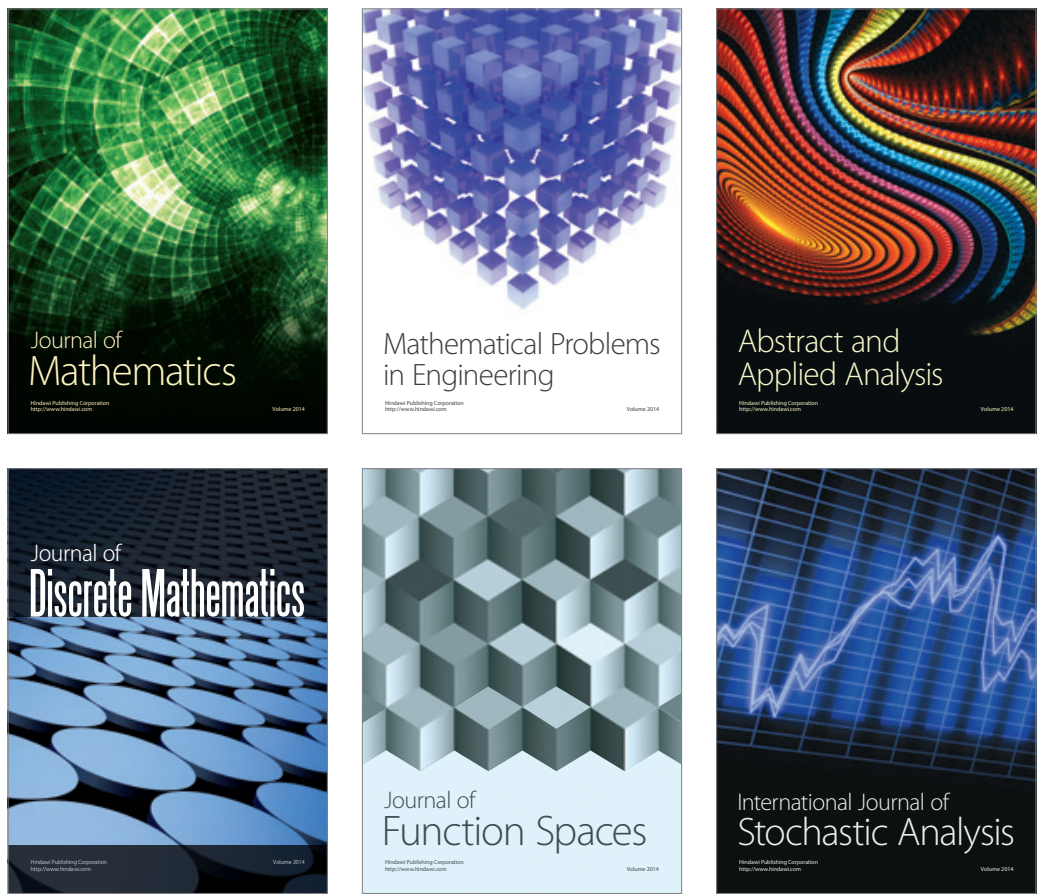

Journal of

Function Spaces

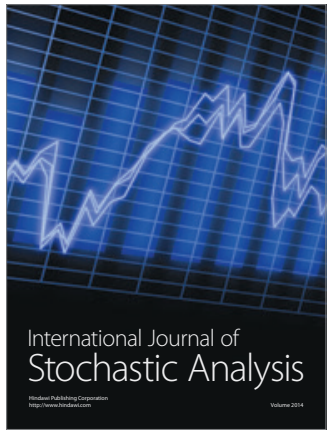

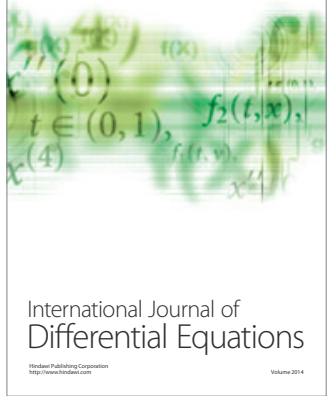
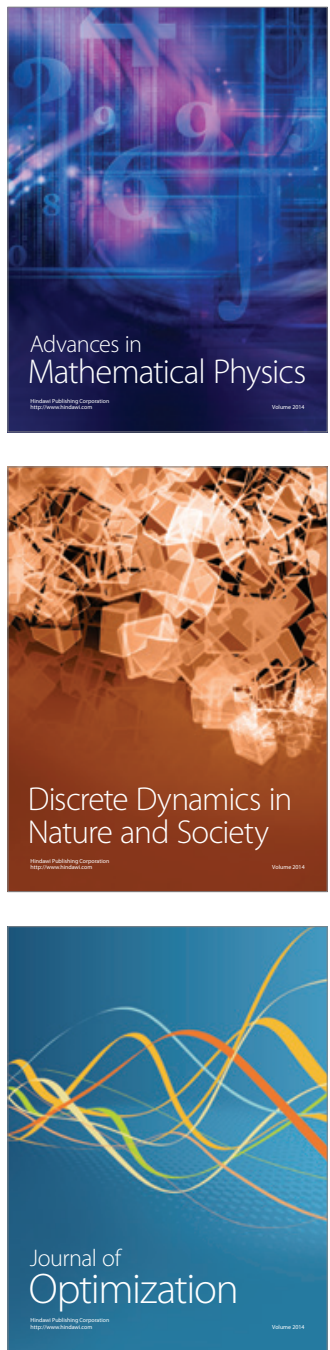